\title{
ANÍSIO TEIXEIRA, PROFESSOR DE PROFESSORAS: UM ESTUDO SOBRE MODELOS DE PROFESSOR E PRÁTICAS DOCENTES (RIO DE JANEIRO, 1932-1935) ${ }^{1,2}$
}

\section{Anísio Teixeira, Teacher of Teachers: a study of teachers life and education (Rio de Janeiro, 1932-1935)}

Diana Gonçalves Vidal ${ }^{3}$

\section{Resumo}

Com o objetivo de compreender, de maneira exploratória, como os saberes e as práticas instauradas no curso de preparo docente organizado por Anísio Teixeira, no Instituto de Educação do Rio de Janeiro, entre 1932 e 1935, marcaram suas alunas, servindo-lhes de mote para elaboração e reelaboração de sua trajetónia profissional, este artigo recorre a fontes orais e escritas e se arrisca no desenho de uma metodologia de pesquisa. A narrativa foi organizada em quatro partes. Na primeira, o lugar de instalação do trabalho profissional de Teixeira na formação de professores é em breves traços delineado. Selecionaram-se apenas os aspectos da história da constituição do Instituto de Educação tidos como necessários ao estudo. Na segunda, exploram-se os contornos dessa prática docente entretecendo documentação escrita e oral. A terceira parte debruça-se sobre a problemática das fontes. A guisa de comentários finais, o texto se interroga sobre a relação entre modelos de professor e a construção de práticas docentes.

Palavras-chave: História da educação; Formação docente; História oral; Vida de professores.

1 Agradeço aos colegas do Núcleo Interdisciplinar de Estudos e Pesquisas em História da Educação (NIEPHE) a oportunidade de debater este texto e as sugestões oferecidas.

2 Este artigo está sendo reeditado a pedido do editor, porfalhas técnicas, agora, conforme versão original. Publicado anteriormente neste periódico, na v. 5, n.14, p.13-34, jan/abr. 2005.

3 Professora livre docente em história educação na Faculdade de Educação da USP e Presidente da Sociedade Brasileira de História da Educação (SBHE). Departamento de Filosofia da Educação e Ciência da Educação. Av. da Universidade 308 - Butantã CEP: 05508-900 Contato: (11) 3091-3195

E-mail: dvidal@usp.br 


\section{Abstract}

In order to understand how knowledge and practices created in the Teachers School, organized by Anísio Teixeira, in the Institute of Education of Rio de Janeiro, between 1932 and 1935, had marked its pupils and how they were used to model students professional trajectory as teachers, this article appeals to the oral and written sources aiming to draw a methodology of research. The narrative was organized in four parts. In the first one, the history of Institute of Education is in brief traces delineated. In second, the contours of his practice as a professor are explored, using written and oral documents. The third part is about the methodology of oral sources. As final comments, the text interrogates about the relation between teachers' models and teachers' practices.

Keywords: History of education; Teachers education; Oral history; Teachers life.

O Dr. Anísio foi um modelo intelectual para mim. Isso não quer dizerque eu me pareça com ele ou que o conteúdo das minhas aulas sejam... não. Eu realmente o tenho até hoje como meu modelo intelectual. Tenho uma admiração profunda por ele. Porque ele era ao mesmo tempo de uma capacidade espantosa de apresentar os temas... Ele era um homem de uma simplicidade, de uma modéstia incomparável. De modo que Dr. Anísio para mim é uma espécie de ídolo.

Iva Waisberg Bonow, professora formada no Instituto de Educação, no Rio de Janeiro, em 1934, depois docente nessa mesma Escola, e coordenadora de cursos no Instituto Nacional de Estudos Pedagógicos (INEP) nos anos 1950, em entrevista concedida em 1995, ao comentar a experiência como aluna no curso de magistério, relacionou sua prática docente à influência de um professor: Anísio Teixeira. Ao compor a narrativa sobre o passado, conferindo-lhe um sentido, Iva Bonow tensionava os fios da memória, construindo uma identidade docente por paralelo e contraste a um modelo de professor. Procedimento nada singular. Mesmo antes do surgimento dos estudos, especialmente a partir da década de 1980, que demonstravam a importância das histórias de vida de professores na compreensão de aspectos de sua prática docente, a relevância de modelos positivos (e negativos) de docência, dentre os vários elementos formadores da escola, era destacada por educadores (GOODSON, 1992, p. 2). 
Anísio Teixeira, professor de professoras: um estudo sobre modelos de professor e práticas docentes ...

Efeito de um julgamento posterior, após décadas de convivência, que lhe permitiram, em outro momento da entrevista, afirmar: "Nós éramos próximos, muito próximos. Ele foi meu professor em mais de uma disciplina e eu escrevi muito sobre ele, Dr. Anísio. E havia uma afinidade muito grande, intelectual, entre uma aluna e um professor. Eu aprendi muito com ele"; a fala de Bonow mesclava lembranças de aluna às de colega de trabalho. Entre $1952 \mathrm{e}$ 1964, Anísio Teixeira assumiu a diretoria do INEP, no mesmo período em que Iva coordenava cursos na instituição.

Deslindar essas várias temporalidades constituintes do ato de rememorar é impossível. Principal característica da fonte oral, a representação que o depoente constrói de sujeitos (inclusive ele mesmo) e fatos vividos é o que os transforma em personagens e acontecimentos do passado. Os alertas de Bourdieu (1996) contra a ilusão biográfica, que supõe na unicidade do corpo biológico o uno identitário, podem ser estendidos aos dados relatados. É o sujeito da narrativa que lhes atribui significados, renovados à medida que se alteram as relações passado-presente, "processo contínuo de reconstrução e tran sformação das experiências relembradas" (THOMSON, 1997, p. 57). Pois a memória, como afirma Ricoeur (2000, p. 733), não está ligada apenas a um eu, nem é coletiva no sentido que lhe confere Halbwachs, mas plural, "atribuição múltipla da lembrança a uma diversidade de pessoas gramaticais".

A dinâmica do depoimento, entretanto, não se resume ao diálogo do narrador consigo mesmo (rememoração). Ao contrário é conformada também pela presença do pesquisador. $\mathrm{O}$ depoente não representa o passado para si, mas para um outro que o provoca. Há assim uma dupla subjetividade na fonte oral, posto que resulta de um relacionamento no qual depoente e investigador estão imbricados (PORTELU, 1981, p. 101). Por isso, Portelli (1981, p. 100) chama a atenção para a diferente credibilidade dos depoimentos. Sua verdade repousa nas condições de produção do relato. São o momento vivido pelo depoente e a situação de entrevista que produzem os possíveis da versão narrada.

Tomados aqui com tais precauções, os depoimentos de Iva Waisberg Bonow e de outras antigas alunas do Instituto de Educação, no momento em que Teixeira atuou na Escola de Professores, entre 1932 e 1935, e que trazem como marcante, em sua formação, a figura do professor Anísio, não são utilizados como senda que permita o resgate de uma prática docente. Permeados por partilhas profissionais estendidas a outros campos de atuação educativa, bem como por leituras de obras do educador, os depoimentos oferecem-nos construções de uma presença elaborada na ausência: relatos sobre personagens que se entrecruzaram múltiplas vezes na trajetória profissional (e de vida). O professor Anísio toma emprestadas as características do superior hierárquico e do intelectual de prestígio. Na rememoração, essas identidades se borram e se reconstroem. 
Prestam-se os depoimentos, no entanto, como índices para a compreensão de maneiras como os saberes e as práticas instauradas no curso de preparo docente organizado pelo educador marcaram as alunas, servindo-lhes de mote para elaboração e reelaboração de sua trajetória profissional. Associados a outras fontes como programas, bibliografias, relatórios e anotações da lavra de Teixeira, localizadas no CPDOC, auxiliam-nos a perceber os contornos de uma prática docente e os significados a ela atribuídos pelas alunas. Vale destacar que produzida no interior da cultura escrita e marcada pela racionalidade moderna, a escola é atravessada pela oralidade, mas pouco dela se preserva (especialmente em tempos em que gravadores e vídeos não se haviam difundido largamente na sociedade). Relatórios, cadernos, diários de classe, anotações guardam registros e trazem vestígios dessa oralidade: forma como se operacionalizaram em gestos e falas as propostas pedagógicas da aula. Investigar uma prática docente pretérita é o desafio deste artigo.

Anne-Marie Chartier (2000) citando Bourdieu, "não é fácil falar da prática de outra forma que não de maneira negativa", e Michel de Certeau, "ao subir, descer, girar ao redor das práticas, alguma coisa escapa sem cessar, que não pode ser dita nem ensinada, mas deve ser praticada", indaga-se sobre a possibilidade de uma pesquisa histórica tratar cientificamente as práticas escolares. Questiona-se sobre a maneira como conduzir investigações que, ao mesmo tempo invadam a caixa-preta da escola e evitem análises que ora deslizem para o anacronismo, concebendo o passado na sua identidade com o presente - deduzindo fazeres pretéritos de práticas escolares contemporâneas-; ora, apóiem-se na mera empiria, descrevendo exaustivamente situações de sala de aula.

Pretendendo destacar elementos que tendam a desenhar uma metodologia de pesquisa sobre as práticas escolares e superar o suposto da escola como realidade conhecida, Anne-Marie Chartier aposta em uma direção de trabalho que para além de inventariar as invariantes da forma escolar, de debruçar-se sobre o repertório estrutural dessa gramática da escola, possa elaborar um meta-discurso que permita falar da escola na escola, que possibilite descrever os fazeres ordinários deslocando a atenção das observações aos dizíveis, às modalidades de dizer ou escrever (VINCENT, 1980; TYACK; CUBAN, 1999DE CERTEAU, 1994).

De certo, esta é uma empreitada delicada e talvez pouco suscetível de sucesso. Por isso mesmo, este texto assume uma dimensão de ensaio, tanto no que concerne à narratividade com que foi construído, quanto no que tange ao próprio exercício metodológico da análise: seguidas aproximações ao objeto. A escrita apresenta, assim, alguma dispersão. No entanto, talvez seja esse caráter exploratório que possa vir a oferecer uma contribuição ao estudo sobre antigas práticas escolares docentes. 
Deve-se considerar, ainda, que é difícil apartar a atuação de Anísio como professor de seu envolvimento com a política educacional, posto que nesse mesmo período era Diretor Geral do Departamento de Educação do Distrito Federal, Rio de Janeiro, e de sua atividade como escritor, visto que então elaborava os originais de Educação progressiva (uma introdução à philosophia da educação), editado pela Coleção Biblioteca Pedagógica Brasileira, da Companhia Editora Nacional, em 1933. Por outro, a cautela não permite justapor os vários papéis, supondo a coincidência. Os distintos lugares de produção do discurso anisiano requerem o reconhecimento de interlocutores e estratégias diferenciadas. Os procedimentos que "têm por função conjurar seus poderes e perigos, dominar seu acontecimento aleatório, esquivar sua pesada e terrível materialidade" precisam ser levados em consideração na compreensão desses discursos, postos a circular em um mesmo momento histórico e enunciados por um mesmo sujeito histórico. Ainda que o presente texto não insista nessa análise, a precaução em perceber, mais do que perscrutar, as dimensões do político, do intelectual e do professor, perpassa a escrita e de forma tênue, por momentos, se anuncia (FOUCAULT, 1999, p.9).

$\mathrm{O}$ artigo foi dividido em quatro partes. Na primeira, o lugar de instalação do trabalho profissional de Anísio Teixeira na formação de professores é desenhado. Selecionaram-se apenas os aspectos da história da constituição do Instituto de Educação tidos como necessários ao estudo. Análises mais abrangentes sobre a temática foram realizadas em outras publicações, o que, acredito, dispensa uma problematização mais extensa aqui ${ }^{3}$. Na segunda, exploramse os contornos dessa prática docente entretecendo documentação escrita e oral. A terceira parte debruça-se sobre a problemática das fontes. À guisa de comentários finais, o texto se interroga sobre a relação entre modelos de professor e construção de práticas docentes.

\section{Instituto de Educação do Rio de Janeiro}

Constituído, em 1932, pela integração do Jardim de Infância, Escolas Primária, Secundária e de Professores, o Instituto de Educação, elevava a formação para magistério ao nível superior no Brasil, através do decreto 3.810, de 19 de março de 1932, assinado pelo próprio Anísio.

Ao mesmo tempo que valorizava o preparo docente, no âmbito de uma, ainda que pouco definida, ciência pedagógica, o Instituto criava estratégias de profissionalização docente, propostas como modelares. É certo que nos vários estados brasileiros, durante a República, e mesmo antes de sua instauração, no Império, houve o empenho na constituição de Escolas Nor-

${ }^{3}$ Ver Vidal (2001). 
mais como modelos para congêneres nacionais e que a legislação que fundava o Instituto de Educação inspirava-se em referências da escola ativa, partilhadas em maior ou menor grau por outras reformas empreendidas nos anos 1920 e 1930 no Brasil. Entretanto a proposta assumia um lugar destacado no cenário nacional não apenas porque era instalada na capital da República logo após a criação do Ministério da Educação e Saúde, em 1930, mas também porque a promulgação do decreto 3.810 era realizada no exato dia em que saía a público o Manifesto dos Pioneiros da Educação Nacional. Neste, várias das formulações do decreto eram sugeridas ${ }^{4}$.

Rigorosa seleção externa e interna de futuras professoras - o feminino aqui é imperativo, uma vez que o artigo 60, do decreto 5.000, de 11 de julho de 1934, restringia a, no máximo, 10\% a matrícula de homens na Escola de Professores - e rituais de distinção, implementados no Instituto, como o destaque às melhores alunas, tendiam a conformar um ideal docente e de magistério, em que ciência e arte se articulavam. Afastada do primado da vocação inata, a concepção de docência defendida por educadores atuantes na Escola, como M. B. Lourenço Filho e Anísio Teixeira, insistia na eficiência da formação profissional, voltada às especificidades do exercício do magistério, centrado na reflexão sobre prática pedagógica. A arte de ensinar, dimensão prática da docência, se entrelaçava, em posição de igualdade, à ciência da educação ${ }^{5}$.

Antes de atuar como professor no Instituto e de assumir a Diretoria do Departamento de Educação carioca, Anísio havia realizado, entre 1928 e 1929, durante 10 meses, estudos no Teachers College, da Universidade de Colúmbia, Nova Iorque, onde recebera o título de Master of Arts. Aluno de Kilpatrick, passou a freqüentar autores como William James, Bertrand Russel, Wells, Thorndike, e John Dewey, antigo professor de Kilpatrick (NUNES, 2000: 138). Dessa experiência colheu, dentre outras influências, a valorização dos cursos de Matéria como formadores para a docência. Implantados na Escola de Professores do Instituto de Educação, esses cursos eram assim caracterizados por Teixeira (1934, p. 7):

As matérias, nas escolas normais, não devem ser ensinadas com o caráter do ensino de nível secundário, nem com o caráter especializado do ensino de nível superior ou universitário. São ensinadas do ponto de vista da profissão do magistério. Se o grau do magistério é o primário, os cursos de matérias serão cursos especiais em que se ministre o conhecimento da matéria apropriada às crianças da escola primária, e o conhecimento das dificuldades

Esta questão vê-se ampliada no artigo de Vidal;Rodrigues (2003).

A análise é aprofundada em Vidal (2000b). 
Anísio Teixeira, professor de professoras: um estudo sobre modelos de professor e práticas docentes ...

dessas crianças em aprendê-la, dos métodos especiais de organizá-la, dosála e distribui-la para o ensino, e sempre que possível, da história do seu desenvolvimento e da sua função na educação da infância.

A ênfase na prática docente, arte, e o primado da ciência pedagógica na formação do magistério, para Anísio, ficavam, dessa maneira, denunciados.

Os cursos de Matéria preparavam a futura professora para a atividade de docência, oferecendo-lhe subsídios de ordem científica - conhecimento psicológico, processual e metodológico do ensino - e de ordem do conteúdo - acréscimo e transferência de conhecimentos. No entanto, apesar do caráter marcadamente prático dessas disciplinas, a qualidade da docência só poderia ser aferida e aprimorada na experiência de sala de aula. Daí, a ênfase em Prática de Ensino.

Prática passava a ser uma atividade também científica, com procedimentos determinados, em seqüência estabelecida por professores especialistas em harmonia aos interesses da escola primária, emitidos pelo diretor e pelo corpo docente. Passava a ser disciplina, nomeada como tal, ocupando três trimestres do segundo ano do curso regular de formação de professores, com uma carga semanal mínima de doze horas, estando coordenada às seções de Matéria, e estas, por sua vez, aos princípios gerais que davam substância aos cursos de Filosofia, História, Psicologia e Sociologia Educacionais. Correspondia ao trabalho em laboratório para os cursos de teoria e Matéria.

A cada trimestre, Prática desdobrava-se em uma atividade específica - observação, participação e direção-; com preparo singular. Na primeira fase, observação, as alunas distribuíam-se em grupos, por diferentes salas do ensino elementar e olhavam a situação geral da classe. Uma série de aulas da cadeira de Psicologia Educacional havia sido dedicada, previamente, a disciplinar esse olhar, através do ensino da técnica de observação da atividade infantil. Consistia em exercícios práticos, realizados com o auxílio da projeção cinematográfica.

Depois de assistirem a uma pequena cena, limitada a dois ou três minutos, anotavam as alunas os fatos observados. Nos primeiros ensaios, poucas conseguiam registrar toda a sequência dos acontecimentos. Insistíamos, durante várias aulas, na prática de ver e anotar a atividade infantil em vários graus do desenvolvimento. O cinema nos dava a vantagem da correção. (MARINHO, 1959, p. 120-121)

Na Escola Primária, repetiam a experiência. Após a observação, alunas e professora-assistente da Seção de Prática respondiam a questionários, debatidos em grupo. O debate era realizado segundo normas científicas, de forma a coibir o comportamento emocional dos debatedores, privilegiando a racionalidade das intervenções. Para normatizar a atividade, propiciando "o 
domínio de si", Lourenço Filho organizou algumas instruções para uso dos alunos da Escola de Professores, publicadas na revista da Escola, Arquivos do Instituto de Educação, em 1934. Carlos Delgado de Carvalho (1934), também, ocupou-se do assunto, discorrendo sobre o exercício de fichamento considerado importante não apenas na seleção de tópicas de estudo como na organização das intervenções em classe. As marcas desse trabalho podem ser apreciadas no depoimento de Maria Violeta V. Boas incluído no quarto item deste artigo.

Os objetivos dessa primeira fase eram capacitar as alunas-mestres a compreender e analisar a situação da classe observada, na sua organização material e ambiente psicológico, e desenvolver, nas professorandas, o senso crítico para com o próprio trabalho. ${ }^{6}$

No trimestre seguinte, passavam à fase de participação. Durante $20 \mathrm{a}$ 30 minutos, as alunas experimentavam uma situação de ensino. Primeiramente conversavam com a regente da classe que lhes indicava, de acordo com 0 andamento do curso, o tópico a abordarem em sala. Depois, debatiam, ainda com a regente, o conteúdo. A aluna-mestre, então, preparava seu roteiro. A participação era observada por outras alunas-mestres, pela professora regente e pela assistente da Seção de Prática, que anotavam suas observações em questionários especialmente preparados. Continham perguntas sobre a atitude geral do participante, reação dos alunos, conteúdo da aula, processo adotado, sua seqüência e aproveitamento.

Os resultados eram discutidos em grupo: a princípio a professoranda realizava uma autocrítica, depois expunham-se as observações das colegas e professores. Ao todo, cada aluna chegava a participar de oito a dez situações de ensino e a observar mais de sessenta. Objetivava a disciplina, além da introdução de hábitos de autocrítica, pôr as professorandas em contato direto com classes, em situações estudadas, planejadas e controladas, de maneira a despertar-lhes a compreensão da marcha da aprendizagem, habilitando-as a saber analisar momentos oportunos de motivação, de exercícios de criação, fixação ou revisão; e utilizar recursos de tempo, material e programa.

No último trimestre, vinha o momento da direção de classe. Turmas eram entregues à responsabilidade direta da aluna-mestre por três horas. Nesse período, além de expansão das capacidades docentes, a disciplina preocupava-se em habilitar as professorandas na prática de escrituração e correspondência escolar e no uso de biblioteca e museu. Os questionários eram substituídos por relatórios realizados pelas alunas-regentes, suas colegas e professora-regente da classe. As constantes avaliações e críticas das situações de ensino/aprendizagem faziam com que as professorandas repensassem sua prática, tentando aprimorá-la, incorporando a observação dos pares e professores.

${ }^{6}$ PRATICA de ensino. Arquivos do Instituto de Educação, v.1, n. 3, p. 357, mar. 1937. 
Anísio Teixeira, professor de professoras: um estudo sobre modelos de professor e práticas docentes ...

Tal atividade crítica por parte das alunas, entretanto, não se resumia à autocrítica ou à avaliação dos pares e das professoras primárias. As professorandas eram também chamadas a opinar sobre o próprio curso. Em um questionário realizado em 1934, coube às professorandas emitirem pareceres sobre seção de Prática de ensino. Dentre algumas respostas coligidas por Léa Castro (1986, p. 84-86), ao inquérito, despontaram críticas ao deficiente estudo das matérias, sob o ponto de vista da escola elementar; à falta de análise dos programas; ao excessivo número de aulas (que impossibilitava seu bom preparo) e ao esquecimento de aspectos das matérias estudadas na Escola Secundária, necessários à atividade docente. Ainda nesse mesmo ano, responderam ao inquérito sobre a validade ou não do uso de testes de múltipla escolha como avaliações de disciplinas em lugar das tradicionais provas escritas.

As alunas, assim, eram instadas, em diversos momentos, a refletir sobre sua prática e de seus pares e superiores, emitindo pareceres e, assim, adaptando-se às necessidades de uma civilização em mudança (como queria Kilpatrick) ou de uma educação progressiva (como preferia Anísio).

Nesse sentido, a atuação direta de Anísio Teixeira como professor de Filosofia da Educação na Escola de Professores reforçava algumas das práticas implantadas no Instituto. Como político da educação e intelectual, Teixeira ajudara a constituir um lugar de preparo docente, no Rio de Janeiro, que se queria atual e exemplar. Agira na externalidade do Instituto de Educação, garantindo-lhe condições de funcionamento e discutindo sua orientação de ensino. Superando a distância entre diretriz (política e teórica) e prática, atuava, também, na internalidade da Escola, como professor de vários cursos, consolidando aspectos de uma proposta de formação para o magistério, pensada como inovadora. É esta última atuação que se quer investigar.

\section{"A educação e o espírito moderno"}

Este era o título que encimava uma lista de dez temas do curso oferecido na Escola de Professores, por Anísio Teixeira, no último trimestre do ano de 19347. O currículo da Escola, organizado em dois anos, era dividido em disciplinas de estudo extensivo (durante todo um ano letivo), como História da Educação, Música, Desenho e Educação Física, Recreação e Jogos; e intensivo (apenas um curso a cada trimestre), como Biologia Educacional, Psicologia Educacional, Sociologia Educacional, Filosofia da Educação e Introdução ao Ensino - Princípios e Técnicas (este último oferecido apenas no primeiro trimestre do ano), além dos cursos de Matérias e Prática de Ensino ${ }^{8}$.

7 O programa faz parte do Arquivo Anísio Teixeira, CPDOC (CPDOC/FGV, AT/IE, pi 32.00.00, fotograma 0722).

8 Quadros de horários, que seriam muito interessantes para a compreensão da distribuição do tempo entre disciplinas de estudo intensivo e extensivo, infelizmente não foram localizados. 
Ao lado dos temas, uma distribuição em semanas, indicava o tempo suposto como necessário para o desenvolvimento do assunto, entre 0 início de outubro e o fim da primeira quinzena de dezembro. O programa era assim anunciado:
1 - Natureza - Homem - Sciencia
2 - Homem e Sociedade
3 - Experiência e Aprendizagem
4 - Necessidades e Aspirações humanas - sua realização e seus limites
5 - Experiência, vida e educação - educação como reconstrução da experiência
6 - O processo educativo e sua direção
7 - Os objectivos da educação e as matérias de ensino
8 - O programa escolar: sua organização e sua execução
9 - A ordem escolar (disciplina e liberdade)
10 - A escola e a reconstrução da vida humana
(Grifos do autor)

À exceção do primeiro tópico, com a indicação manuscrita 1. ${ }^{\mathrm{a}}$, $2 .^{\underline{a}}$ sem. de outo, os demais eram previstos para realização em uma semana. Ao fim do documento, a data 6/10/934, indicava a coincidência entre a elaboração do curso (ou sua datilografia) e o começo do trimestre. Consistia, portanto, em uma disciplina de estudo intensivo, mas não de caráter introdutório, uma vez que ministrada no fim de 1934.

A análise dos temas permite poucas inferências, mas instiga a reflexão. A relação entre matérias de ensino e objetivos da educação, no item 7 , repõe, de certa maneira, a discussão desenhada anteriormente neste artigo sobre a arte de ensinar. A seqüência dos termos experiência, vida e educação, no item 5, remete ao livro de John Dewey, Vida e educação, publicado pela Edições Melhoramentos, em 1930, com tradução de Anísio Teixeira. Compõe a obra um esboço da educação de John Dewey, elaborado por Teixeira, intitulado "A pedagogia de Dewey", e subdividido em "I - Educação como reconstrução da experiência" e "II - A escola e a reconstrução da experiência”. A primeira subdivisão corresponde exatamente ao enunciado explicativo do tema 5.

Voltemos ao Arquivo. Acompanhando o programa, outros documentos nos permitem esmiuçar um pouco mais os temas. Sob o cabeçalho NATUREZA - HOMEM - SCIENCIA ${ }^{9}$, encontramos um texto cuja forma se assemelharia a um exercício. Datado de 4 de outubro de 1934, antecede em dois dias a datilografia de A educação e o espírito moderno. Composto por 20 enunciados, apresenta como primeiro:

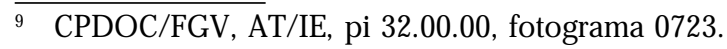


Anísio Teixeira, professor de professoras: um estudo sobre modelos de professor e práticas docentes ...

\section{1 - Considerar o seguinte:}

- O ultimo terremoto, no Japão, causou a morte a mais de 2.000 pessoas;

- Seccas e epidemias dizimam constantemente culturas e criações;

- Trinta milhões de saccas de café foram destruídas no Brasil, para equilíbrio do mercado;

- Suicida-se, no Rio de Janeiro, uma pessoa por dia;

- A saúde e a nutrição, no Brasil, são grandemente deficientes;

e ao mesmo tempo:

- A população do mundo é, dia a dia, maior;

- A riqueza humana é, dia a dia, maior;

- A actividade humana é, dia a dia, mais intensa e mais ampla;

- A insatisfação e inquietação, por maiores que sejam, são menores do que o desejo de fazer, de realisar, de ser activo homem?

a) que revelam esses factos quanto à natureza do mundo e à do

b) ajustam-se ellas, uma a outra, ou são contradictórias?

c) precariedade e contingência são indispensáveis ao homem para que elle viva, ou a segurança e a fatalidade é que verdadeiramente o tornariam feliz?

d) qual a verdadeira origem das differentes doutrinas a respeito?

(Grifos do autor)

Em todo o Arquivo, não pude encontrar listas de subitens aos tópicos do programa. No entanto, quatro páginas de enunciados como esse, datilografadas ou manuscritas, rearranjam os problemas selecionados. Combinações novas, alterando um ou outro aspecto do enunciado, indiciam que as tópicas abordadas eram freqüentemente reelaboradas. Exemplos da vida cotidiana serviam de mote às indagações, construídas sempre de forma aberta, como em c) e pressupondo a análise da aluna, como em b).

Tentando compreender essa organização dos conteúdos do curso, busquei informações nas entrevistas efetuadas com antigas alunas. Iva Bonow trouxe-me alguns elementos.

O Anísio era um pensador. Admirável. Tinha uma modéstia... uma modéstia tão rara, tão chocante, que a gente até esquecia que ele era modesto. Havia muita coisa que ele dizia, pérolas, que pensava que eram bagulhos, mas não eram. Era difícil. Não era fácil, não. Não era um professor fácil de entender. Mas depois que nós amadurecíamos, nos começávamos a pescar as pérolas. Agora, não era fácil. Não era fácil de entender, fácil de estudar. Ele sempre obrigava a gente a coisa mais importante que é pensar. É importante. É difícil. 
Repetidamente, Iva Bonow usou a expressão não era fácil. A dificuldade a que se reportava talvez se articulasse a que eu sentia em compreender as páginas de enunciados do Arquivo. Em lugar de uma seqüência de assuntos a abordar, a aula era elaborada como um conjunto de problemas a discutir, onde a presença ativa da aluna, indagada sobre diferentes questões, sobressaía à voz do professor. A organização lógica, o fio que interligava os vários enunciados era construído por Anísio. Mas a maneira aberta da formulação dava margem ao debate, incitando a uma reflexão que mesclava conceitos filosóficos a problemas práticos. Bagulhos e pérolas passam a ter sentido: entremeadas em discussões aparentemente banais, questões filosóficas eram tratadas.

Discorrendo sobre o Sentido e finalidade da philosofia da educação ${ }^{10}$, Anísio Teixeira, apoiado em Dewey, afirmava que a filosofia surgiu da necessidade de reconciliar os conhecimentos empíricos e positivos dos tradicionais e religiosos - em essência poéticos - da humanidade. Constituiu-se historicamente não como uma atividade desinteressada do espírito humano para a pesquisa da verdade, mas como um esforço da inteligência para justificar com fundamentos racionais, costumes crenças e instituições tradicionais. A mudança que se operava nos tempos modernos, era a transformação da filosofia de "instrumento especializado de pesquiza de con cepções engenhosas de justificação e racionalização de verdade tradicionaes, em um instrumento intellectual de trabalho cada um de nós". (p.8).

Concluía: "A philosofia desistiu das causasfinaes e da verdade eterna para chegar em meio aos homens e debater com elle os seus problemas usuaes" (p. 10).

Era essa a direção que Anísio procurava dar aos trabalhos em classe - debate dos problemas usuais da humanidade - e, por isso, a organização das aulas em torno de enunciados como o citado anteriormente, que incitavam 0 recurso à oralidade. A oralidade, entretanto, é somente possível na escola moderna, enraizada na cultura escriturária, se concebida em consonância ao registro escrito (DE CERTEAU, 1994). Nessa medida pode-se compreender, não apenas o esforço de datilografar os enunciados, cuja versão manuscrita também se encontra no Arquivo Anísio Teixeira, mas a redação, em máquina de escrever, do Sentido e finalidade da philosofia da educação: conferência de abertura do curso sobre filosofia da educação, oferecido por Teixeira. Tarefa que toma relevo, especialmente quando cotejamos com o depoimento de Iva Bonow a respeito do surgimento do sistema de mimeógrafo.

Tradução. Havia poucos [trabalhos em português]. Nisso apareceu o sistema do mimeógrafo. Tá entendendo? Os textos que eram traduzidos para 0 português por diversas pessoas... e as traduções eram texto de... para os alunos. Você nunca ouviu isto?

${ }^{10} \mathrm{CPDOC} / \mathrm{FGV}, \mathrm{AT} / \mathrm{IE}$, pi 32.00.00, doc I-25. 
Anísio Teixeira, professor de professoras: um estudo sobre modelos de professor e práticas docentes ...

Utilizada para a divulgação das traduções, possivelmente a estratégia era estendida à reprodução de textos de aula. A hipótese é corroborada pela introdução ao texto datilografado Educação e personalidade humana ${ }^{11}$.

Temos examinado nas três aulas anteriores os problemas geraes da finalidade da philosofia da educação, da vida [ilegível] processo e da vida moral, justa ou feliz. Vamos, agora, examinar o problema da pessôa humana. Como ella se fórma.

- Natureza da sua conducta ou comportamento.

A discussão poderá visar o thema: EDUCAÇÃO E PERSONALIDADE HUMANA.

Leia a exposição junto. Formule suas duvidas ou questões.

Vale destacar, aqui, que nas orientações de leitura, o trabalho sobre 0 texto não remetia a questões fechadas, mas abria-se à formulação, por parte da aluna, de indagações. Ao mesmo tempo, a sugestão do tema de discussão vinha regida pelo verbo poder, servindo de convite à reflexão.

Várias outras estratégias ainda foram utilizadas pelo Instituto de Educação para a divulgação de material escrito: a criação em 1934 da revista Arquivos do Instituto de Educação, voltada para a publicação de trabalhos e investigações sobre ensino e organização escolar, realizados por professores e alunas da Escola; o incentivo pecuniário, incorporado ao salário, oferecido aos professores que tivessem seus livros aprovados pelo Conselho Técnico do Instituto; e a compra de livros no Brasil e no exterior, de forma a atualizar a Biblioteca12 ${ }^{12}$ A essas podemos associar, iniciativas que atravessavam o fazer da Escola, como a atuação de M.B. Lourenço Filho na direção geral do Instituto de Educação, e na direção de sua Escola de Professores, ao mesmo tempo que coordenava a Bibiliotheca de Educação, para a Edições Melhoramentos.

No caso específico sobre o qual nos debruçamos, vejamos como essas estratégias funcionavam. Vida e educação, de John Dewey, como já afirmado, fora traduzido e contava com estudo inicial elaborado por Anísio Teixeira, para a Editora Melhoramentos, em 1930. A Biblioteca do Instituto de Educação possuía dois exemplares e, depois de Introdução ao estudo da Escola Nova, de Lourenço Filho, era o livro mais indicado nos programas das diversas disciplinas da Escola de Professores (VIDAL, 2001). Sentido e finalidade da philosofia da educação com algumas adaptações foi publicado às páginas finais de Educação progressiva (uma introdução à Filosofia da Educação), de Anísio Teixeira, editado, como afirmado anteriormente, pela Cia. Editora Nacional, em 1933. Dois exemplares também foram incorporados pela Biblioteca, sendo a obra incluída nos programas disciplinares. Os dois livros

11 CPDOC/FGV, AT/IE, pi 32.00.00, doc I-17, fotograma 0743.

12 Sobre essas estratégias ver Vidal (2001). 
estavam disponíveis nas livrarias no momento em que Teixeira ofereceu 0 curso A educação e o espírito moderno. Eram, portanto, acessíveis tanto para aquisição quanto para consulta às alunas. As obras eram possivelmente usadas, não apenas no curso, como posteriormente na vida profissional das educadoras formadas no Instituto (como em outras escolas).

Haydée Gallo Coelho, que concluiu o magistério no Instituto de Educação, em 1934, e foi professora de sua Escola Primária daquele momento até sua aposentadoria, escrevera em seu caderno de aulas, em 1939:

Diz Anísio Teixeira no final do seu livro Educação Progressiva: “O professor de hoje tem que usar a legenda do filósofo: nada que é humano não me é estranho. Tem que ser estudioso dos mais embaraçosos problemas modernos, tem que ser estudioso da civilização, tem que ser estudioso da sociedade e tem que ser estudioso do Homem, tem que ser, enfim, filósofo".

Ao ler o trecho, durante a entrevista realizada em 1999, exclamou: Isso é o Anísio Teixeira! A identificação de Anísio com parágrafo selecionado revelava-se tão interessante quanto o próprio teor da escrita. Voltamos não apenas ao texto datilografado da conferência inaugural, afinal publicada com algumas alterações no livro em foco, mas aos termos do curso oferecido em 1934 - homem e sociedade - e a alguns dos enunciados organizadores das aulas. Ao recortar o trecho e identificá-lo a Anísio, Haydée Coelho talvez estivesse indiciando aspectos reiteradamente tratados pela docência de Teixeira.

Corroborando a preocupação já enunciada do estímulo à reflexão e à postura ativa das alunas frente o conhecimento, em depoimento, Maria Violeta Vilas Boas, integrante também da turma formada em 1934, depois Diretora de Escola no Instituto de Educação, na década de 1940, narrou um evento particular: uma situação de avaliação.

Anísio Teixeira foi meu professor de Filosofia da Educação. Ele fez a prova mais inteligente que eu já vi. Era uma prova de coerência de afirmações. Eram questões de múltipla escolha, está entendendo?Quando eu saí, eu me lembro que um grupo de colegas me perguntou "o que você achou?" "Eu não sei que achei." Ou melhor. "Eu não sei que ele vai achar. Eu sei que eu fiz o que eu achava que devia ser." E depois eu tinha razão, porque ele fez a correção pela coerência das respostas... pela coerência que nós tivemos, porque as questões eram formuladas por opções e você escolhia. Essas opções batiam ou não batiam umas com as outras. Eu talvez não devesse mencionar isso, mas eu e mais quatro colegas ficamos sendo chamadas de "big five". Porque fomos as cinco primeiras de notas. O Anísio era uma cabeça, uma daquelas pessoas que não se repetem. 
A prática docente de Anísio parecia incitar uma postura reflexiva às alunas, da mesma maneira que o estímulo à autocrítica nos exercícios realizados pela Seção de Prática de Ensino. Nesse sentido, coadunava-se à orientação geral dos estudos no Instituto de Educação. No depoimento de Helena Silva de Oliveira sobre as aulas na Escola Secundária, a preocupação com o ensino ativo era reiterada.

Então, o Carlos Werneck levou uma cobra d'água, para nascerem os ovos e dos ovos nascerem as cobrinhas. O diretor, na ocasião, ficou morrendo de medo, que era o Lourenço Filho. Ele ficou apavorado. Ele levava sapo para nos vermos como era o sapo. Quando apertava determinadas, partes a defesa do sapo em soltar aquele veneno de defesa. Então a gente tinha que proteger. Eram o mais possível aulas vivas, tá? Não era coisa morta. Tinha um esqueleto. Os ossos lá todos armados direitinho para nós lá na hora de exame saber dizer o nome daqueles ossos todos. Havia uns professores que diziam eles não vão ser professores... não vão ser médicas, para que isso? Não é? Em Higiene também nos aprendíamos a reprodução de micróbios com uma rapidez, se nos botássemos uma coisa que se estava deteriorando, nos acompanhávamos pelo microscópio. Era tudo assim.

No entanto, a prática de Anísio apresentava matizes que a distinguiam de outros professores da casa como a fórmula bagulhos e pérolas, de Iva Bonow, parecia indicar. O procedimento aberto do tratamento dos temas em aula, fazendo dialogar constantemente a teoria e os problemas cotidianos, e o estímulo à liberdade de pensar, mais que o incitamento à observação das alunas em classe, emergiam como diferença.

\section{Questões de método}

Aceitar o desafio de discorrer sobre práticas escolares pretéritas requer enfrentar a delicada questão das fontes. Circunscrever a possibilidade do empreendimento à recolha de depoimentos cria um limite à pesquisa: ela é apenas realizável para a história do tempo presente. 0 recurso às fontes escritas permite ampliar a investigação a tempos mais remotos. Nesse sentido, lidar com programas, deixando-se sensibilizar pela materialidade dos objetos utilizados na condução dos trabalhos na disciplina, como os exercícios e, neste caso, os textos mimeografados, oferece um alargamento da documentação.

Por outro lado, acolher ponderações sobre a narratividade dos documentos escritos, como as elaboradas por Arlette Farge (1989) para o Arquivo Judiciário abrem perspectivas à análise. Particularmente são pertinentes suas asserções quando argumenta que: 
o arquivo não informa a verdade, mas sobre a verdade" (p. 40) ou quando afirma que "as frases são também eventos, porque foram elaboradas para fazer crer" (p. 99) ou "porque reenviam às formas de comunicação usuais onde a linguagem está em correspondência às culturas e aos saberes particulares e pessoais (p. 103).

Sua reflexão incita a revisitar o registro escrito não apenas à procura do que ele omitiu, mas principalmente daquilo que relatou, atentando para a maneira como o relato foi composto. A premissa repousa sobre o entendimento de que as formas de comunicação também informam sobre as práticas sociais (e no nosso caso, escolares).

Mas se as fontes orais não são o único recurso à análise, não devem ser desprezadas sempre e quando seu uso seja possível. Há que tomá-las com as precauções necessárias, já mencionadas na introdução, mas que aqui retomo, a partir do diálogo entre o objeto de estudo e os depoimentos citados.

Os relatos utilizados neste artigo foram produzidos por antigas alunas de Anísio Teixeira que se declaravam influenciadas por sua prática docente, considerando-o como modelo de bom professor. Os discursos, assim, não escaparam à teia do enaltecimento à figura do educador.

Incidiam ainda essas falas sobre um momento específico das trajetórias de vida e de profissão das depoentes. Abordavam o curso de preparo para a docência, marco inicial de sua atuação no magistério e, provavelmente, identitário da ação profissional, tanto no que concerne ao trabalho em sala de aula quanto no que tange às ocupações que assumiram em outras esferas da educação carioca e nacional (nas quais partilharam também da companhia pessoal e intelectual de Anísio).

Haydée Gallo situava a importância do Instituto de Educação em sua trajetória profissional da seguinte maneira:

Então, eu fiz o primeiro ano ginasial ali. Antes de terminar, portanto em outubro, inauguraram a Escola Normal, na rua Mariz e Barros e nós todas fomos pra lá. A escola mudou-se. Então, passou aquela maravilha, aquele Instituto. Ali foi... pra adiante eu... acabei meu curso lá. Fui convidada pra trabalhar. Isso você já sabe, eu já tinha te contado antes. Fui convidada com a... com um pequeno grupo... grupo que se destacou mais na parte de... de técnicas de ensino, prática de ensino. Essa coisa toda e... as primeiras aulas que nós demos que foram assistidas pelos... pelos professores e tal. Então, eles convidavam as que achavam que estavam mais adaptadas ou com melhores condições de lecionar naquela escola, que era a escola modelo. Agora você imagina aquele prédio maravilhoso, aquelas salas todas novinhas, as carteiras. Tudo maravilhoso. Bom. Então, fomos nós pra lá. Eu acabei o meu curso e fiquei lá. Depois fui convidada pra trabalhar lá. Eu e um grupinho 
pequeno. Ficamos trabalhando... a primeira turma logo que me deram... foi primeira série. Quando a diretora, dona Orminda Marques... Você vê a sorte, peguei essa gente toda. D. Orminda Marques era diretora do primário. Ela... me convidou... um dia, pra uma reunião. Eu fui sem saber pra que era. Era pra dizer que nós tínhamos sido... o dr. Lourenço Filho tinha indicado as... melhores notas na prática de ensino, foram convidadas pra trabalhar no Instituto. Eu graças a Deus estava nesse grupo.

Referiam-se os depoimentos também a uma época consagrada pelo campo educacional e pelos estudos sobre formação docente, particularmente no Rio de Janeiro, como fundadora de uma nova concepção de magistério. Foi, então, pela primeira vez, elevada a formação docente ao nível superior. Maria Violeta Villas Boas avaliava, assim, a experiência do Instituto:

A criação do Instituto de Educação foi uma verdadeira revolução no ensino normal no estado. Digamos, no país. Embora, São Paulo também tivesse 0 Instituto de Educação. Não foi a primeira Escola Normal, não. A primeira Escola Normal foi no... até no nordeste. E depois houve uma Escola Normal aqui na corte. E, inclusive, foi posterior a uma que foi do estado do Rio. Bom, mas Escola Normal, sim. Agora, Instituto de Educação foi uma revolução por quê? No ensino normal. Porque ela criou uma nova estrutura e nova dinâmica que imprimiu um nível e uma qualidade de ensino diferente do que vinha acontecendo. Porque antes a Escola Normal era, sem dúvida nenhuma utilíssima, mas ela era... pequena fundamentação e não entrava no âmago das técnicas e processos de ensino. Era uma coisa que ficava um pouco na superfície. Era um... era uma contribuição necessária, de uma certa maneira boa, porque não se fazia outra coisa. Mas, na verdade, não preenchia os requisitos a... necessários ao futuro professor primário. E o Instituto, não. $\mathrm{O}$ Instituto deu uma nova dimensão, tanto no sentido de uma riqueza maior de currículo, como de tratamento desse currículo e das disciplinas que 0 compunham.

Por fim, eram depoimentos elaborados no diálogo estabelecido com uma pesquisadora de São Paulo, mais jovem, e interessada na experiência levada a efeito no Instituto de Educação do Rio de Janeiro. A referência ao Instituto de São Paulo trai a dupla subjetividade da fala de Maria Violeta. O enaltecimento da proposta e dos personagens a ela associados era seguramente um dos motes do relato.

No entanto, não se pode supor que os depoimentos fossem inverídicos e que não se projetassem distinções entre os educadores envolvidos no projeto do Instituto. Nos relatos, as diferenças eram marcadas. Por exemplo, Iva Bonow comparando dois professores, Lourenço Filho e Anísio, afirmava: 
Porque até Psicologia eu aprendi com o Dr. Anísio, apesar de ter sido aluna por três anos consecutivos com o Lourenço Filho. Porque o Lourenço, a matéria constava do currículo, do programa. Compreende? Então, eram estudos sistemáticos. Já o Anísio, o Anísio era um pensador. Admirável.

A clareza das problemáticas que atravessam a produção do relato oral apenas singulariza o trabalho com ele efetuado, destacando as peculiaridades de seu uso. Os relatos orais não visam assegurar a precisão dos fatos histónicos, como datas, possivelmente mais acuradas nos registros escritos. Mesmo nestes, fontes diferentes, por vezes, apontam informação diversa que é preciso elucidar. Os depoimentos objetivam registrar os sentidos com que os sujeitos históricos construíram a narrativa e se construíam ao narrá-la. No dizer de Portelli (1981, p. 100), "o que faz a história oral única e necessária é sua trama", ou seja, a "maneira como o narrador arranja os materiais de maneira a contar uma história".

\section{Comentários finais}

Por fim, cabe tecer algumas considerações acerca da importância dos modelos de professor na construção de práticas de docência. Nesse caso, 0 depoimento de Maria Violeta Villas Boas é exemplar. Ela afirma ter aprendido a fazer fichamento com o professor Delgado de Carvalho na Escola de Professores do Instituto.

Em 1933 ou 34, eu fui aluna do Delgado de Carvalho. Delgado de Carvalho, ele tinha... foi uma experiência interessantíssima, que eu nunca vi o individuo se beneficiar da dificuldade de comunicação... linguística. Não é pessoal. Ele tinha um raport maravilhoso com as alunas, mas ele tinha vindo de uma formação americana, quer dizer, em inglês e francês. Então, quando ele entrou nas nossas salas, ele tinha dificuldade de encontrar as palavras no português.[...] Ele botava os livros dele e outros livros, indicava outros livros da biblioteca e dava problemas. Era tudo... era o que nós aprendíamos de teórico, logo se transformava, tinha um apoio dos estudos feitos pelos grupos e tendo... com o seu coordenador, cada um fazia sua ficha resumo, sua ficha... ah, ou síntese ou mesmo ficha copia. Discutia no grupo, depois o grupo chegava a uma conclusão, formulava uma ficha com essa síntese das conclusões. Depois, os grupos se reuniam, isso que é estudo seminarizado. Os grupos se reuniam com outros grupos e apresentavam o produto. E, geralmente, dois grupos estudavam aquele assunto. Eu nunca me esqueço, porque mudou muito... Eu nunca me esqueço de um dos problemas que nós... que eu... que o meu grupo desenvolveu, que era a... uma afirmação, para a gente concordar, discordar e dar embasamen... argumentos. "A escola... a Igreja é uma das mais conservadoras instituições sociais." 
Anísio Teixeira, professor de professoras: um estudo sobre modelos de professor e práticas docentes ...

Anos mais tarde, na sua prática como intelectual, Maria Violeta retraçava a experiência, apropriando-se do procedimento.

Era mais ou menos assim. Eu me acostumei a trabalhar com ficha, até hoje eu não vou para uma palestra que eu não prepare um roteiro. Geralmente, eu não mexo. Mas é que na hora que eu sento para fazer o roteiro, com uma introdução, um desenvolvimento e uma conclusão, eu arrumo na minha cabeça... Eu aprendi isso com Delgado de Carvalho. Arrumo na minha cabeça o que eu vou dizer. Eu acho que a maior prova de desconsideração que você deve... você pode dar ao público, é você chegar lá e improvisar.

\section{A prática docente transformou-se em livro.}

Mas no Instituto eu... como eu fazia, isso que eu estou dizendo a você, esta orientação para o estudo com as alunas, eu produzi com esse material que fui preparando... Elas recebiam umas súmulas e eu, depois, transformei essas súmulas em livros. Então, essas súmulas tratavam de técnicas de leitura e técnicas de fichamento e técnicas... e técnicas de seminário. Então, eu... eu transformei isso num trabalho, num trabalho chamado Como estudar. E o trabalho foi publicado pelo SENAC, depois que eu entrei para lá.

Compreender as práticas docentes no amplo ciclo da experiência individual e coletiva impõe não apenas a insistência no estudo da importância das instituições de formação docente na difusão de modelos culturais, como o relatado por Maria Violeta Villas Boas, mas também no interesse em investigar as experiências formadoras apropriadas ao longo da trajetória escolar. Nesse caso, os alertas de Thompson (2002) sobre as diferenças entre alunos adultos e crianças, realçando que os primeiros trazem para a relação pedagógica uma experiência escolar anterior, parecem oferecer ainda outros campos à pesquisa, alargando para a toda a escolarização a construção de uma ou várias experiências de ser professor.

Mas, a investigação sobre as práticas docentes deve-se deixar sensibilizar ainda pela observância dos ritos e valores associados ao magistério, constituintes de uma tradição inventada recriada constantemente como respaldo à ação docente (HOBSBAWM, 1997). Aqui, os modelos positivos de docência constituem e são constituídos por regras partilhadas pela comunidade que lhe conferem uma certa identidade, provisória, apesar de compreendida como imemorial, o que reforça a concepção de marcos fundadores associados em geral a uma percepção do magistério como imutável. (Estes procedimentos assumem particular importância na análise deste artigo que explora uma escola modelo - o Instituto de Educação do Rio de Janeiro - e um intelectual de prestígio - Anísio Teixeira-.) São possivelmente efeitos do que Portelli (1981) 
denominou de trama. Pois, a docência se exercita como uma prática oral e as identidades do magistério se constroem (também) pela convivência cotidiana de professores no interior (ou fora) da escola e da troca de experiências boas e más. Há, assim, constantemente histórias a contar.

A representação da própria prática docente bem como da de professores modelo como estáveis exerce a função de assegurar uma perenidade da ação individual e coletiva do magistério, a despeito das alterações por que passam fruto das apropriações realizadas no curso da vida (pessoal e) profissional. Essa ambigüidade talvez seja a mesma que encontramos no depoimento de Iva Bonow incluído como epígrafe a este artigo: O Dr. Anísio foi um modelo intelectual para mim. Isso não quer dizer que eu me pareça com ele ou que o conteúdo das minhas aulas sejam... não. Afinal, ao investigar de modelos de docência estamos lidando com as várias temporalidades da vida (e da memória) e os vários sujeitos do viver (e do lembrar).

\section{Entrevistas utilizadas} Janeiro.

Haydée Gallo Coelho, realizada em 23 de abril de 1999, no Rio de

Maria Violeta Coutinho Villas Boas, realizada em 26 de setembro de 1994, no Rio de Janeiro. Janeiro.

Iva Waisberg Bonow, realizada em 02 de fevereiro de 1995, no Rio de

Helena Silva de Oliveira, realizada em 08 de julho de 1994, em São José dos Campos (SP).

\section{Referências}

BOURDIEU, P. A ilusão biográfica. In: Ferreira, M.; Amado, J. Usos e abusos da história oral. Rio de Janeiro, RJ: FGV. 1996.

CASTRO, Léa Maria Sussekind Viveiros de. Uma escola de professores: formação de docentes na Reforma Anísio Teixeira (1931-1935) - Mestrado de Educação/PUC-RJ. Rio de janeiro,1986.

CHARTIER, Anne-Marie. Fazeres ordinários da classe: uma aposta para a pesquisa e para a formação. Educação e Pesquisa, v. 26, n. 1, jan./jun, 2000.

DE CERTEAU, M. A invenção do cotidiano. Petrópolis: Vozes, 2004. 
DELGADO DE CARVALHO, Carlos. A dissertação em sala de aula. Arquivos do Instituto de Educação, Brasília, v.1, n.1, p. 105-108, jun., 1934.

FARGE, Arlette. Le goût de l'archive. Paris: Seuil, 1989.

FOUCAULT, M. A ordem do discurso. São Paulo, SP: Loyola, 1999.

GOODSON, Ivor (org.). Studying teacher's lives. Nova Iorque: Teachers College Press, 1992.

HOBSBAWM, E. A invenção das tradições. In: Hobsbawm, E. e Ranger, T. A invenção das tradições. São Paulo, SP: Paz e Terra, 1997.

LOURENÇO FILHO, M.B. A discussão nos trabalhos de seminários. Arquivos do Instituto de Educação, Brasília, v. 1, n. 1, p. 109-120, jun., 1934.

MARINHO, Heloisa. Lourenço Filho e o ensino da Psicologia. In: ASSO CIAÇÃO Brasileira de Educação. Um educador brasileiro: Lourenço Filho. São Paulo, SP: Melhoramentos, 1959.

NUNES, Clarice. A poesia da ação. Bragança Paulista: EDUSF. 2000.

PORTELU, A. The peculiarities of Oral History. History Workshop, 12. 1981. Proceedings... 1981. p. 96-107.

PRÁTICA de ensino. Arquivos do Instituto de Educação, v. 1, n. 3, 357, mar. 1937.

RICOEUR, P. Histoire et mémoire. Annales Histoire, Sciences Sociales, v. 55, n. 4, jul./ ago., 2000.

TEIXEIRA, Anísio Educação progressiva: uma introdução à philosophia da educação. São Paulo, SP: Cia. Ed. Nacional, 1933.

. Como ajustar os 'cursos de matérias' na escola normal com os 'cursos de prática de ensino'. Boletim de Educação Pública, Brasília, v.3 n. 5-6, a. 7, jul./ dez., 1934.

THOMSOM, A. Recompondo a memória: questões sobre a relação entre história oral e as memórias. Projeto História 15, abr., 1997.

THOMPSON, E.P. Os românticos: a Inglaterra na era revolucionária. Rio de Janeiro, RJ: Civilização Brasileira, 2002.

TYACK, David; CUBAN, Larry. Why the grammar of schooling persists: tinkering toward utopia. [S. 1.]: Harvard Univ. Press, 1999.

VIDAL, Diana G. (org.). Na batalha da educação: correspondência entre Anísio Teixeira e Fernando de Azevedo (1929-1971). Bragança Paulista: EDUSF. 2000a. 
. P rática, experimental e científica: a formação docente na administração Anísio Teixeira da educação carioca (1931-1935). In: SMOLKA, Ana Luíza B.; MENEZES, M. Cristina. Anísio Teix eira: provocações em educação. Campinas: Autores Associados/ EDUSF. 2000b.

- O exercício disciplinado do olhar: livros, leituras e práticas de formação docente no Instituto de educação do Distrito Federal (1932-1937). Bragança Paulista: EDUSF. 2001.

VIDAL, D.G.; Rodrigues, Rosane N. A casa, a escola ou o trabalho: o Manifesto e a profissionalização feminina no Rio de Janeiro (1920-1930). In: XAVIER, M. C. (org.). 70 anos do manifesto dos pioneiros: um legado educacional em debate. Rio de Janeiro,RJ: FGV, 2003.

VINCENT, Guy. L' école primaire française. Lyon: Presses Universitaires de Lyon, 1980. 